\title{
Impact of Cr-poisoning on the conductivity of $\mathrm{LaNi}_{0.6} \mathrm{Fe}_{0.4} \mathrm{O}_{3}$
}

\author{
M.K. Stodolny ${ }^{\mathrm{a}}$ \\ B.A. Boukamp \\ D.H.A. Blank \\ F.P.F. van Berkel ${ }^{\mathrm{a}}$
}

${ }^{a}$ Energy Research Centre of the Netherlands (ECN), Biomass, Coal and Environmental Research, P.O. Box 1, 1755 ZG Petten, The Netherlands

${ }^{b}$ University of Twente, Department of Science and Technology \& $\mathrm{MESA}^{+}$, Institute for Nanotechnology,

P.O. Box 217, 7500 AE Enschede, The Netherlands

Published in Elsevier 196 (2011) 9290-9298 


\title{
Impact of $\mathrm{Cr}$-poisoning on the conductivity of $\mathrm{LaNi}_{0.6} \mathrm{Fe}_{0.4} \mathrm{O}_{3}$
}

\author{
M.K. Stodolny ${ }^{\mathrm{a}, *}$, B.A. Boukamp ${ }^{\mathrm{b}}$, D.H.A. Blank ${ }^{\mathrm{b}}$, F.P.F. van Berkel ${ }^{\mathrm{a}}$ \\ a Energy research Centre of the Netherlands (ECN), Hydrogen and Clean Fossil Fuels, P.O. Box 1, 1755 ZG, Petten, The Netherlands \\ ${ }^{\mathrm{b}}$ Department of Science and Technology $\mathcal{E} M E S A^{+}$Institute for Nanotechnology, University of Twente, 7500 AE, Enschede, The Netherlands
}

\section{A R T I C L E I N F O}

\section{Article history:}

Received 22 April 2011

Received in revised form 27 June 2011

Accepted 23 July 2011

Available online 29 July 2011

\section{Keywords:}

SOFC cathode

Cr-poisoning

Cr vapor transport

LNF

SOFC interconnect

Perovskite

\begin{abstract}
A B S T R A C T
This study demonstrates the significant impact of $\mathrm{Cr}$ on the electronic conductivity of a $\mathrm{LaNi}_{0.6} \mathrm{Fe}_{0.4} \mathrm{O}_{3}$ (LNF) porous cathode layer at $800^{\circ} \mathrm{C}$. Vapor transport of $\mathrm{Cr}$-species, originating from a porous metallic foam, and subsequent reaction with LNF, results in a decrease of the electronic conductivity of the LNFlayer. $\mathrm{Cr}$ has been detected throughout the entire cross-section of a $16 \mu \mathrm{m}$ thick LNF layer, while $\mathrm{Ni}$, besides its compositional distribution in the LNF layer, has also been found in enriched spots forming $\mathrm{Ni}$-rich metal oxide crystals. Transmission electron microscopy revealed that $\mathrm{Cr}$ is gradually incorporated into the LNF-grains, while Ni is proportionally expelled. Electron diffraction performed in the center of a sliced grain showed the initial rhombohedral crystal structure of LNF, whereas diffraction performed close to the edge of the grain revealed the orthorhombic perovskite crystal structure, indicating a $\mathrm{Cr}$-enriched perovskite phase. Progressive $\mathrm{Cr}$ deposition and penetration into the LNF grains and necks explains the electronic conductivity deterioration. The impact of $\mathrm{Cr}$-poisoning on the electronic conductivity of the LNF porous layer is considerably smaller at $600^{\circ} \mathrm{C}$ than at $800^{\circ} \mathrm{C}$.
\end{abstract}

(C) 2011 Elsevier B.V. All rights reserved.

\section{Introduction}

The perovskite $\mathrm{LaNi}_{0.6} \mathrm{Fe}_{0.4} \mathrm{O}_{3}$ (LNF) is considered a candidate cathode and interconnect coating material for various intermediate temperature SOFC (IT-SOFC) systems where relatively cheap interconnect materials such as chromia-forming ferritic stainless steels are used. High electronic conductivity and thermal expansion coefficient matching that of zirconia [1], together with claimed high Cr-resistance [2-4] are the properties of LNF that enable its use as cathode current collecting layers, interconnect protective coatings and/or electrochemically active cathode layers. Furthermore, the use of LNF material as a cathode is recommended for metalsupported SOFCs [5], due to claimed high $\mathrm{Cr}$ tolerance and good performance obtained for LNF sintered at low temperatures [6].

In order to ascertain reliable operation of LNF in a Cr-containing environment, such as in an IT-SOFC stack, a study regarding the actual tolerance of LNF towards $\mathrm{Cr}$ was undertaken, especially in the view of recent findings demonstrating the occurrence of solidstate reactivity of LNF with chromia at $800^{\circ} \mathrm{C}$ : It has been observed that LNF is chemically unstable at $800^{\circ} \mathrm{C}$ when it is in direct contact with $\mathrm{Cr}_{2} \mathrm{O}_{3}$ as $\mathrm{Cr}$-cations enter the perovskite phase, replacing first $\mathrm{Ni}$ - and then Fe-cations $[7,8]$. The present study investigates the extent to which the electronic conductivity of the LNF layer is affected by the exposure to $\mathrm{Cr}$. Transport of $\mathrm{Cr}$ is known to take place

\footnotetext{
* Corresponding author. Tel.: +31224 564074; fax: +31 224568489.

E-mail addresses: stodolny@ecn.nl, maciej.stodolny@gmail.com (M.K. Stodolny).
}

by solid-state diffusion of $\mathrm{Cr}$-cations and by vapor phase transport of mainly $\mathrm{CrO}_{3(\mathrm{~g})}$ and/or $\mathrm{CrO}_{2}(\mathrm{OH})_{2(\mathrm{~g})}[9,10]$. The aim of this study is to describe and clarify the mechanism of the attack of volatile $\mathrm{Cr}$ species and its impact on the electronic conductivity of a porous LNF-layer. The electronic conductivity is monitored under dry synthetic air conditions. In order to accelerate the $\mathrm{Cr}$-poisoning impact, active flushing of the gas atmosphere over the LNF-layer has been prevented, with the aim of building an equilibrium pressure of the volatile $\mathrm{Cr}$-species above the LNF-layer. On basis of literature data it is expected that the main volatile $\mathrm{Cr}$-species in dry synthetic air is $\mathrm{CrO}_{3(\mathrm{~g})}[9,10]$. The exposed porous LNF layer resembles porous SOFC cathode layers that have been investigated in other studies $[11,12]$. Based on the present study a tentative mechanism for the $\mathrm{Cr}$ attack on the scale of one LNF particle will be presented.

\section{Experimental}

\subsection{Sample preparation}

LNF layers were prepared using $\mathrm{LaNi}_{0.6} \mathrm{Fe}_{0.4} \mathrm{O}_{3}$ powder (Praxair, 99.9\% purity). The mechanical support used during the conductivity measurements was composed of a tape cast $3 \mathrm{~mol} \%$ yttria stabilized zirconia (3YSZ) layer, that was sintered at $1500^{\circ} \mathrm{C}$ for $1 \mathrm{~h}$ resulting in an electrolyte disc of $25 \mathrm{~mm}$ diameter and $90 \mu \mathrm{m}$ thickness, which was subsequently covered with a $2 \mu \mathrm{m}$ thick $\mathrm{Gd}_{0.4} \mathrm{Ce}_{0.6} \mathrm{O}_{1.8}$ (40GDC) layer by means of screen printing followed by sintering at $1300^{\circ} \mathrm{C}$ for $1 \mathrm{~h}$. The LNF powder, after precalcination at $800^{\circ} \mathrm{C}$ for $1 \mathrm{~h}$ in air, was milled and dispersed into an alcohol-binder 


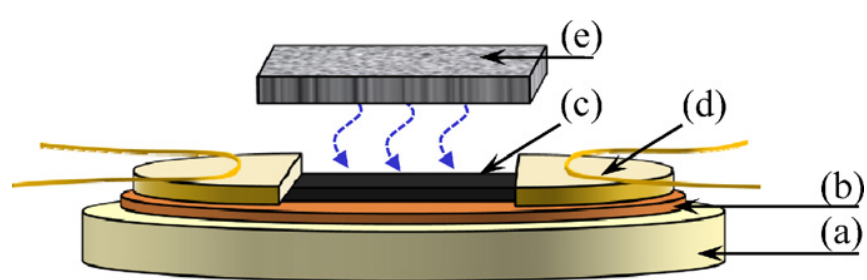

Fig. 1. A schematic drawing of the sample used for the 'semi four probe' electronic conductivity measurements while exposed to a $\mathrm{Cr}$-source. The 3YSZ disc (a) covered with a 40GDC interlayer (b) served as a mechanical support for the LNF layer (c) and gold contacts (d). The porous ferritic ITM-14 foam (e) served as a source of volatile $\mathrm{Cr}$-species (blue dashed arrows). Note that the drawing is not to scale. No active gas flushing took place over the porous LNF layer resulting in a semi-stagnant gas atmosphere above the LNF layer. (For interpretation of the references to color in this figure legend, the reader is referred to the web version of the article.)

solution using a Dispermat (VMA-Getzmann GmbH) milling system. The LNF paste was screen printed on top of the 40GDC intermediate layer and sintered at $1250^{\circ} \mathrm{C}$ for $1 \mathrm{~h}$. The resulting LNF perovskite layer formed a $10 \mathrm{~mm}$ wide strip with a thickness of approximately $15-20 \mu \mathrm{m}$. Subsequently, gold thin foils, onto which gold wires were spot welded to serve as voltage and current probes, were attached at both ends of the LNF perovskite layer with the help of a gold paste (Metalor) and sintered in air at $850^{\circ} \mathrm{C}$ for $3 \mathrm{~h}$ to allow the measurement of the sheet conductivity $[11,13]$. The resulting uncovered LNF layer had a surface area of $10 \mathrm{~mm} \times 10 \mathrm{~mm}$. The prepared sample is shown schematically in Fig. 1.

\subsection{Conductivity measurements}

In order to measure the electronic conductivity each freshly prepared sample was heated in a quartz tube, flushed with dry synthetic air, $20 \% \mathrm{O}_{2}$ (purity $99.6 \%,<7 \mathrm{vpm} \mathrm{H}_{2} \mathrm{O}$ ) and $80 \% \mathrm{~N}_{2}$ (purity $99.999 \%,<4 \mathrm{vpm} \mathrm{H}_{2} \mathrm{O}$ ) at a total flow rate of $100 \mathrm{ml} \mathrm{min}^{-1}$, to the operating temperature of 800 or $600^{\circ} \mathrm{C}$ with a rate of $100^{\circ} \mathrm{Ch}^{-1}$. The construction of the testing equipment was such that no active flushing over the LNF sample took place. After reaching the operating temperature, the impedance was measured using a Solartron 1255 frequency response analyzer in conjunction with a Solartron $1287 \mathrm{~A}$ electrochemical interface in a 'semi four probe' configuration (i.e. the two electrodes had separate current and voltage probe wires). The applied frequencies ranged from $100 \mathrm{kHz}$ to $0.1 \mathrm{~Hz}$ with a signal amplitude of $10 \mathrm{mV}$. The specific electronic conductivity in $\mathrm{S} \mathrm{cm}^{-1}$ was calculated from the sheet resistance of the porous LNF layer and the LNF layer thickness, as determined by SEM, assuming a negligible ionic contribution $[1,14]$. The high frequency intercept in the Nyquist plot (ZView2) was taken as the electronic resistance.

The conductivity measurements were performed as function of time and temperature in a $\mathrm{Cr}$-free (reference) and in a $\mathrm{Cr}$-containing environment. The temperature dependence of conductivity was obtained directly after the exposure experiments. The cooling rate was $100^{\circ} \mathrm{Ch}^{-1}$ with a short dwell time at each data point. For the Cr-poisoning experiments an ITM-14 ferritic FeCr-based alloy in the form of a porous foam (Plansee AG, Reutte, Austria $[15,16]$ ) was used as a $\mathrm{Cr}$ source. The laser-cut foam with dimensions of $14 \mathrm{~mm} \times 10 \mathrm{~mm}$ was pre-oxidized for $100 \mathrm{~h}$ at $800^{\circ} \mathrm{C}$ prior to the experiment to insure the presence of a $\mathrm{Cr}$-containing oxide scale on the metal surface. This $0.7 \mathrm{~mm}$ thick ITM-14 sheet was positioned $1 \mathrm{~mm}$ above the $10 \mathrm{~mm} \times 10 \mathrm{~mm}$ area of the LNF layer without any direct contact, as depicted in Fig. 1. For each of the Cr-poisoning experiments a freshly cut and pre-oxidized ITM-14 foam was used.

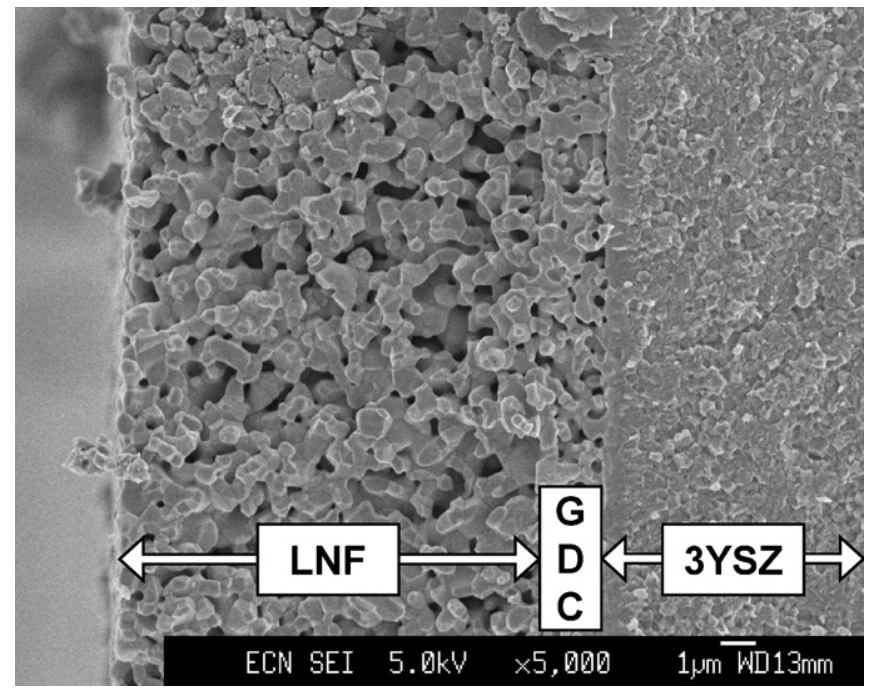

Fig. 2. SEM micrograph of the fractured cross-section of the LNF-GDC-3YSZ assembly.

\subsection{Microstructural and compositional characterization}

The porosity of the as-prepared LNF-layers was obtained from the density of the LNF layer calculated from geometrical dimensions, measured weight and theoretical density of $\mathrm{LaNi}_{0.6} \mathrm{Fe}_{0.4} \mathrm{O}_{3}$.

After carrying out the conductivity measurements the surface, the fractured cross-section and the embedded and polished crosssection of the samples were analyzed by field emission scanning electron microscopy, using a JEOL JSM 6330F FEG-SEM equipped with an EDX detector (ThermoNoran's Pioneer NORVAR). The SEM micrographs of the LNF layers surface were digitally processed with Image [17]. The micrographs were binarized by automatic thresholding and further analyzed to obtain the microstructural features such as particle and neck size distribution statistics.

The elemental composition of the LNF-layers exposed to $\mathrm{Cr}$ was obtained by scraping off the LNF-layer and analyzing the elemental composition of the resulting powder by means of inductively coupled plasma-optical emission spectroscopy (ICP-OES), using a Varian Vista AX PRO CCD.

The Cr-exposed sample chosen for the transmission electron microscopy (TEM) analyses was prepared by the method of Dimple Grinding/Polishing in water-free conditions and argon ion beam etching. TEM analyses were performed using Philips CM300ST-FEG TEM equipped with a Gatan Tridiem energy filter and a Thermo Fisher NORAN System Six EDX analyzer with a Nanotrace EDX detector. All TEM experiments were performed at an acceleration voltage of $300 \mathrm{kV}$, using several modes of operation: general bright field TEM imaging (BF-TEM) with objective aperture (OA), selected area electron diffraction (SAED), and energy dispersive X-ray analysis (EDX) in a static small-spot size mode.

\section{Results and discussion}

\subsection{Microstructure of the LNF layer}

Fig. 2 shows the SEM micrograph of the fractured cross-section of the LNF sample. The LNF layer possessed a homogenous and continuous microstructure with an open granular structure and well-connected grains. The LNF layer exhibited a total porosity of $32 \%$ with an average layer thickness of $16 \mu \mathrm{m}$. The open porosity enabled vapor phase transport of volatile $\mathrm{Cr}$-species into the LNF layer. 
a

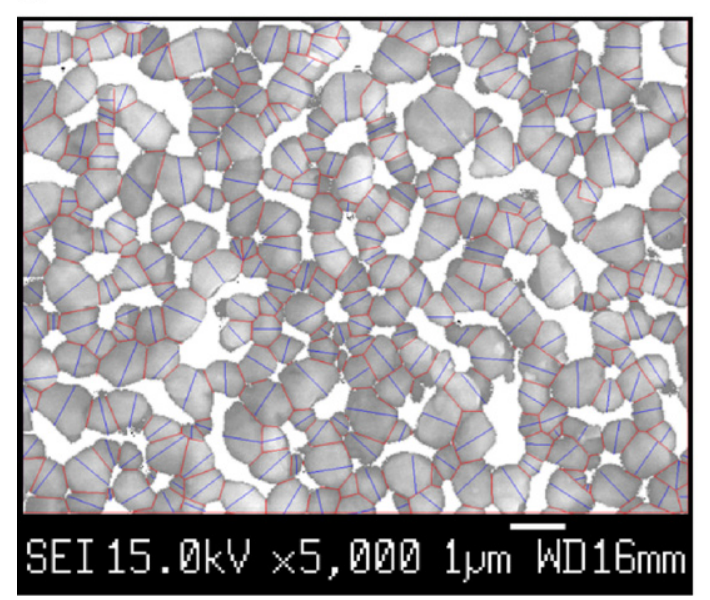

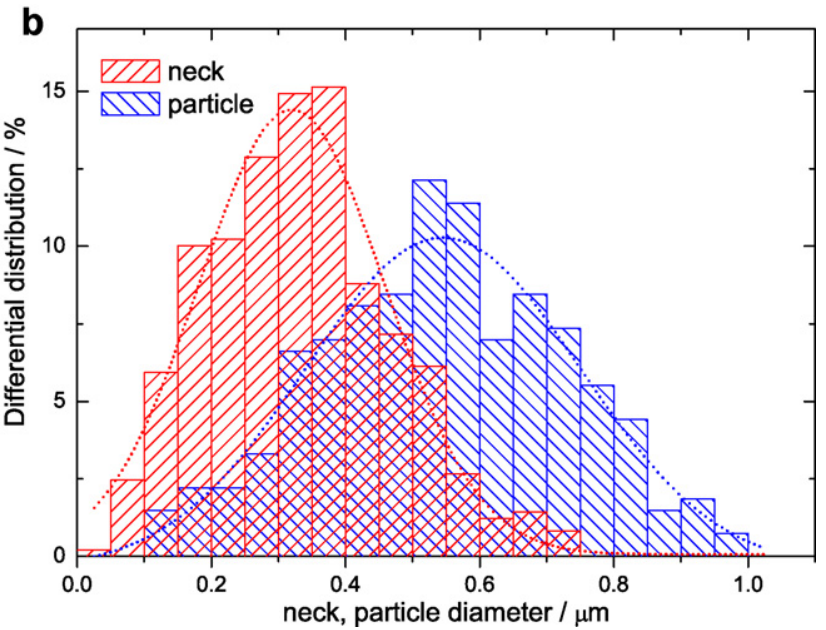

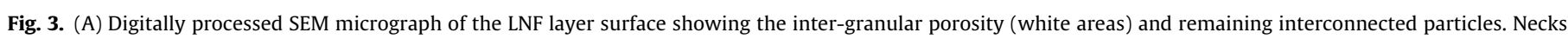

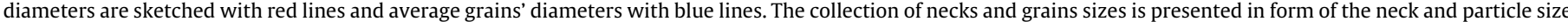

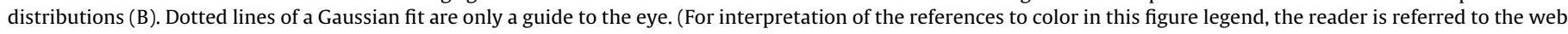
version of the article.)

In Fig. 3A, the digitally processed SEM micrograph of the representative area of the LNF layer surface shows the inter-granular porosity (white areas) and remaining interconnected particles. The sizes of the necks and particles were calculated to create the size distribution statistics as shown in Fig. 3B. The median neck diameter $d(50)$ was $0.33 \mu \mathrm{m}$ and the median grain diameter $D(50)$ was $0.54 \mu \mathrm{m}$.

\subsection{Conductivity evolution of $L N F$ at $800^{\circ} \mathrm{C}$}

\subsubsection{Conductivity evolution of LNF as function of time}

Fig. 4 presents the electronic conductivity evolution with time of the LNF layers at $800{ }^{\circ} \mathrm{C}$ in $\mathrm{Cr}$-free and in $\mathrm{Cr}$-containing atmospheres. The reference sample showed a relatively stable electronic conductivity for a testing period of $250 \mathrm{~h}$. The LNF sample exposed to volatile $\mathrm{Cr}$ species (sample No. 1 in Fig. 4) exhibited a significant loss in the electronic conductivity within the first $50 \mathrm{~h}$, then a semi-linear conductivity decline could be observed in the time period of approximately 100-300 h. Subsequently, a second steep conductivity drop appeared after $320 \mathrm{~h}$ of the exposure to volatile Cr species. In the repeated Cr-poisoning test (sample No. 2 in Fig. 4),

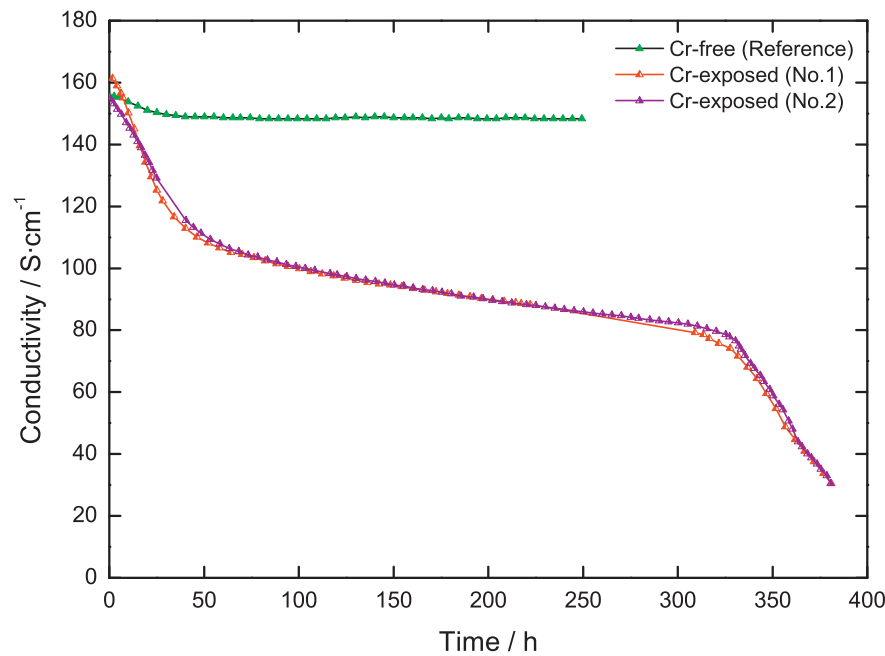

Fig. 4. Electronic conductivity evolution at $800^{\circ} \mathrm{C}$ for the $\mathrm{Cr}$-free and $\mathrm{Cr}$-exposed LNF layers. the shape of the electronic conductivity drop was reproducible with a maximum deviation in time of $3 \mathrm{~h}$, indicating consistent and reproducible results (Fig. 4 ).

\subsubsection{Conductivity as function of temperature}

For both the $\mathrm{Cr}$-free and the $\mathrm{Cr}$-exposed samples, the electronic conductivity $\sigma$ as a function of temperature was measured directly after the exposure at $800^{\circ} \mathrm{C}$ in order to determine the impact of volatile $\mathrm{Cr}$-species on the electronic conductivity behavior of the LNF layer. Fig. 5 shows the relation between $\log (\sigma T)$ versus the inverse absolute temperature. This relationship was chosen because literature indicates that the electronic conductivity $\sigma$ of $\mathrm{LaNi}_{x} \mathrm{Fe}_{1-x} \mathrm{O}_{3}$ series $(x \leq 0.6)$ can be described by the thermally activated small polaron mechanism $[1,18]$ which is generally expressed as:

$\sigma=\frac{1}{T} A e^{-\left(E_{a} / k T\right)}$

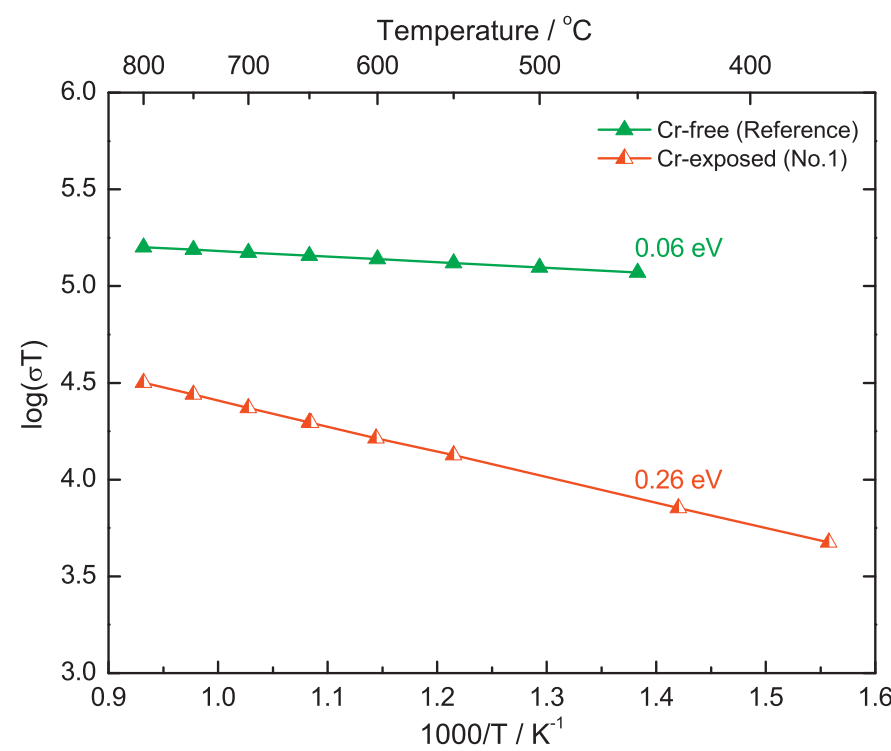

Fig. 5. Temperature dependences of the electronic conductivity for the $\mathrm{Cr}$-free $\left(250 \mathrm{~h}\right.$ at $\left.800^{\circ} \mathrm{C}\right)$ and $\mathrm{Cr}$-exposed $\left(380 \mathrm{~h}\right.$ at $\left.800^{\circ} \mathrm{C}\right) \mathrm{LNF}$ layer. 


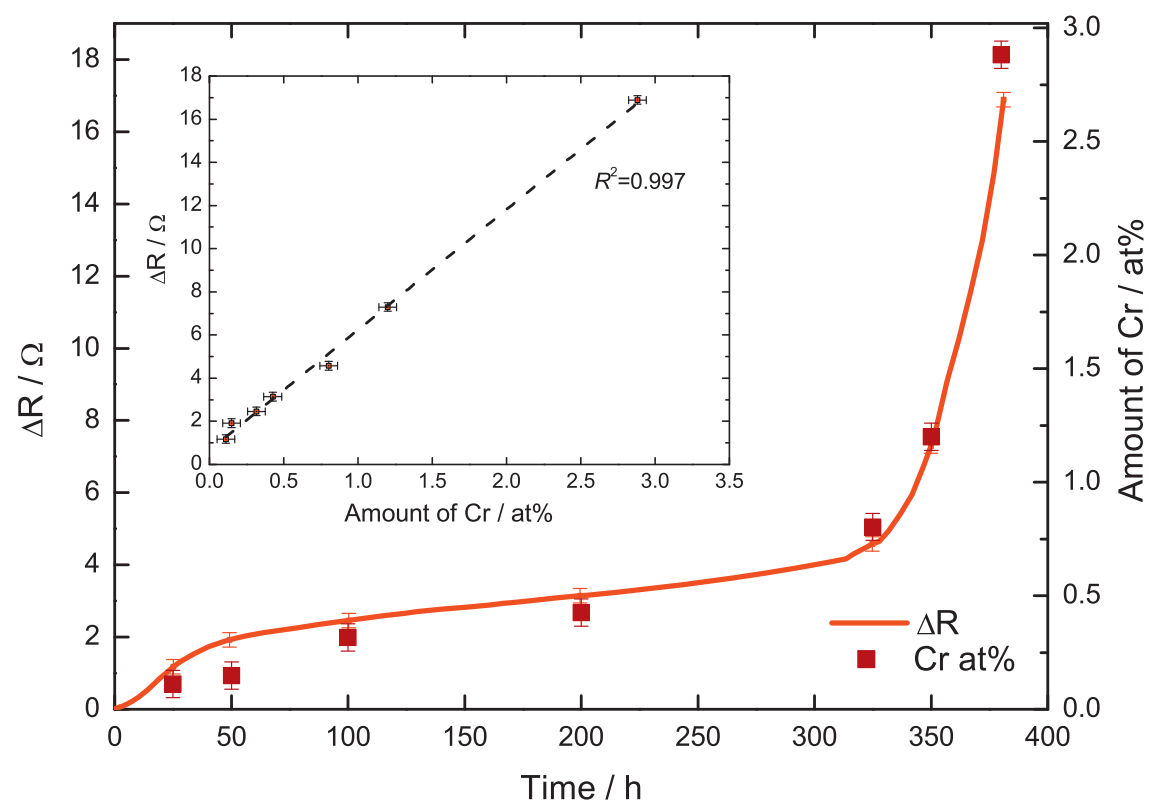

Fig. 6. The increase in the sheet resistance $\Delta R\left(\Delta R=R(t)-R_{\text {initial }}(t=0)\right)$ of the Cr-exposed LNF layer (No. 2) in time plotted together with the amount of deposited Cr. The inset presents directly the correlation of $\Delta R$ versus amount of $\mathrm{Cr}$ deposited in the corresponding time periods in the bulk of the Cr-exposed LNF layers.
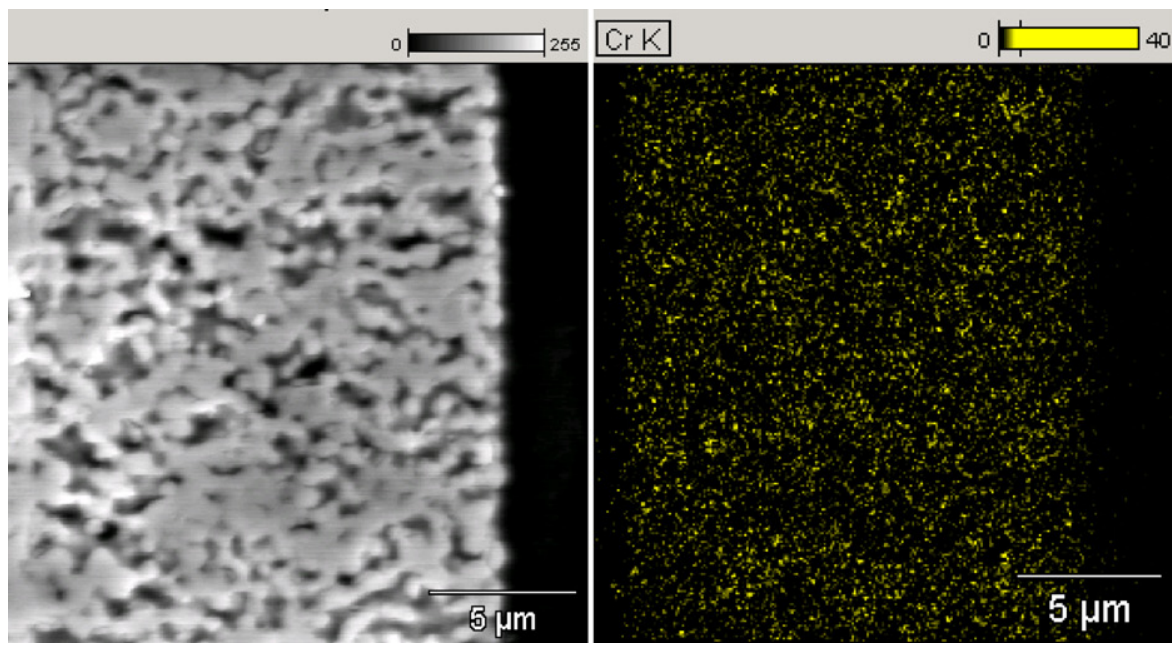

Ni K

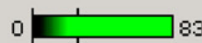

Fig. 7. SEM-EDX elemental mapping of $\mathrm{Cr}$ and $\mathrm{Ni}$ throughout the embedded and polished cross-section of the $\mathrm{Cr}$-exposed LNF layer
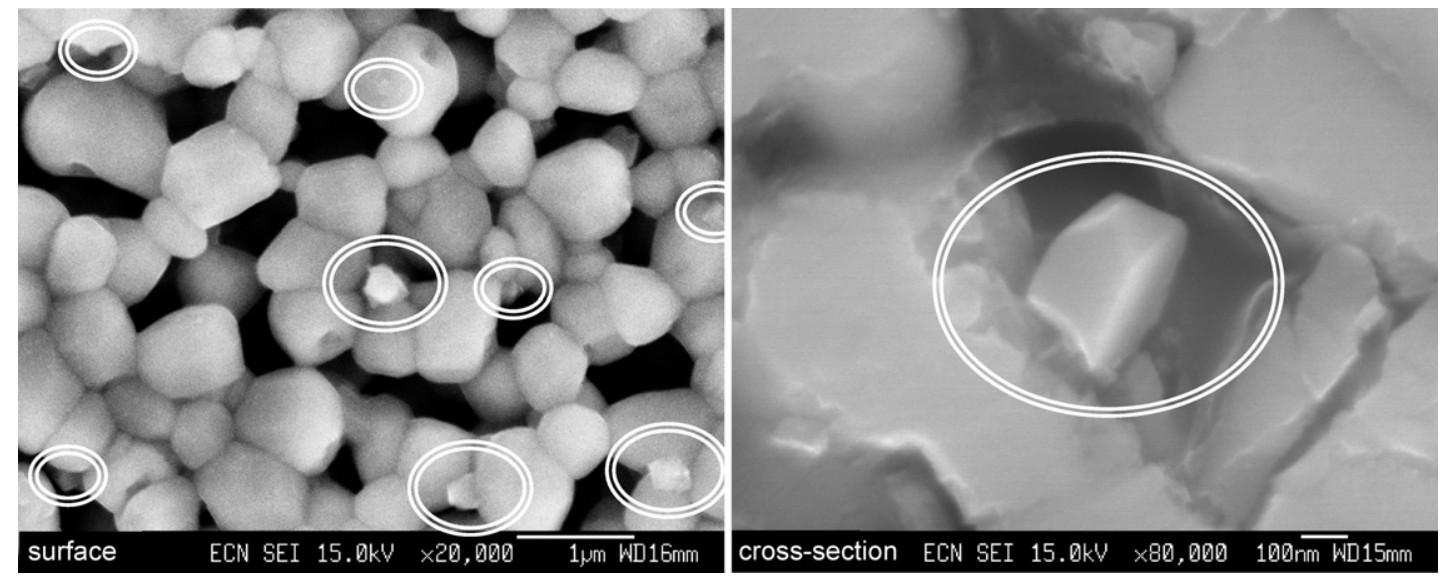

Fig. 8. SEM micrographs of the surface and the embedded and polished cross-section of Cr-exposed LNF layer. Ni-rich oxide crystals are circumscribed. 


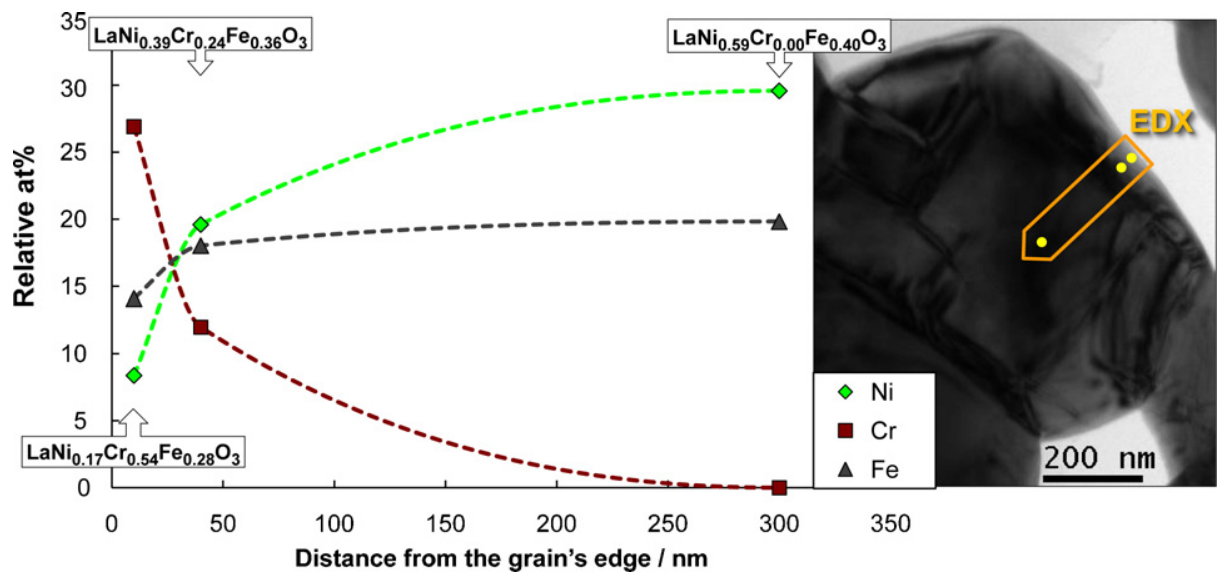

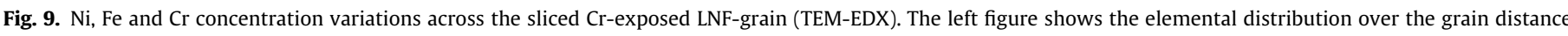

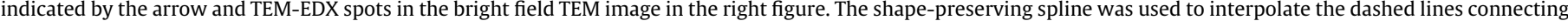
elemental concentration values.

in which $E_{a}$ is the activation energy for small polaron hopping conduction, $k$ is the Boltzmann constant, $T$ is the absolute temperature and $A$ is a pre-exponential factor.

Both the $\mathrm{Cr}$-free and the $\mathrm{Cr}$-exposed samples (No. 1) exhibit linear behavior in the $\log (\sigma T)$ versus 1000/T coordinates (Fig. 5), which is in agreement with the assumed small polaron conduction mechanism. There is a significant difference in the slope of the linear trend between the reference sample and the $\mathrm{Cr}$-exposed sample, hence the effective activation energy increased significantly for the $\mathrm{Cr}$-exposed layer from $0.06 \mathrm{eV}$ to $0.26 \mathrm{eV}$. The activation energy measured for the $\mathrm{Cr}$-free reference porous LNF layer is similar to literature data of LNF $(0.05-0.08 \mathrm{eV})[18,19]$, whereas the $E_{a}$ value of the $\mathrm{Cr}$-exposed layer is comparable to $\mathrm{La}(\mathrm{Fe}, \mathrm{Cr}) \mathrm{O}_{3}$ compounds $(0.20-0.30 \mathrm{eV})[20-23]$.

\subsection{Cr distribution in a Cr-exposed LNF layer}

This section deals with the analysis of the nominal LNF layer composition as a function of the exposure time to volatile $\mathrm{Cr}$ species and the resulting distribution of $\mathrm{Cr}$ throughout the layer.

Table 1 presents the results of the ICP-OES investigation of the LNF powder, $\mathrm{Cr}$-free LNF-layer, and also the Cr-exposed LNF-layers as function of the exposure time. It is important to note that the ratio between La-, Ni-, and Fe-concentration (50:30:20) did not change in any of the $\mathrm{Cr}$ exposure experiments. Hence there was no cation loss from the porous LNF layer during the exposure to $\mathrm{Cr}$-species. As shown in Table 1, the $\mathrm{Cr}$-content increased with the exposure time suggesting that the decrease in the electronic conductivity was related to the amount of $\mathrm{Cr}$ deposited in the layer. Fig. 6 presents the correlation of the increase in the sheet resistance $\Delta R$ of the Cr-exposed LNF layer (No. 2) in time with the amount of $\mathrm{Cr}$ detected in the bulk of the layer in the corresponding time periods. The nearly linear relationship $\left(R^{2}=0.997\right)$ of this correlation (inset in Fig. 6) indicates indeed that the decrease in the electronic conductivity (Fig. 4) was related to the amount of $\mathrm{Cr}$ deposited in the Cr-exposed LNF-layer.

The non-linear time dependent behavior of the electronic conductivity together with the corresponding amount of deposited $\mathrm{Cr}$ indicates that the $\mathrm{Cr}$-incorporation in the LNF-layer is not linear in time. One of the possible explanations of the non-linear $\mathrm{Cr}$-incorporation behavior might be a change in the evaporation behavior of the porous ITM-14 foam-like structure with time, in contrast to a steady $\mathrm{Cr}$ evaporation rate reported for the ITM-14 sheet $[15,16,24]$. To explain this possible change in the Cr evaporation behavior post-test analysis was performed on the exposed ITM-14 porous foams [25]. SEM-EDX analysis revealed that the outer oxide scale formed during the exposure in dry air at $800^{\circ} \mathrm{C}$ changed with time. In case of the ITM-14 foams exposed no longer than $300 \mathrm{~h}$ (in addition to the initial pre-oxidation step of $100 \mathrm{~h}$ ) the outer oxide scale was mainly composed of $(\mathrm{Mn}, \mathrm{Cr})_{2} \mathrm{O}_{4}$. In case of
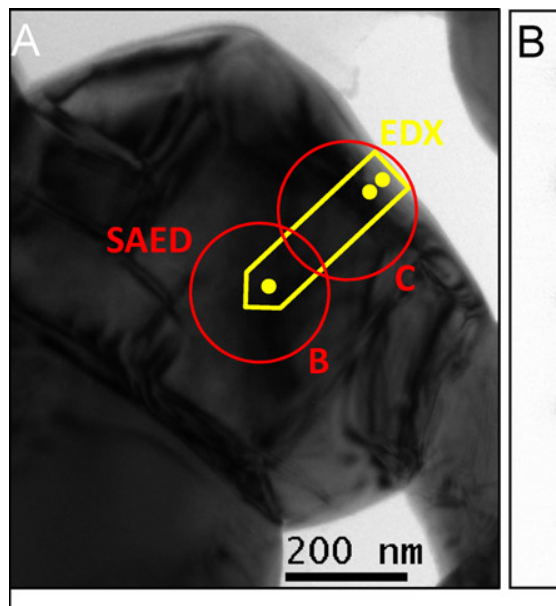

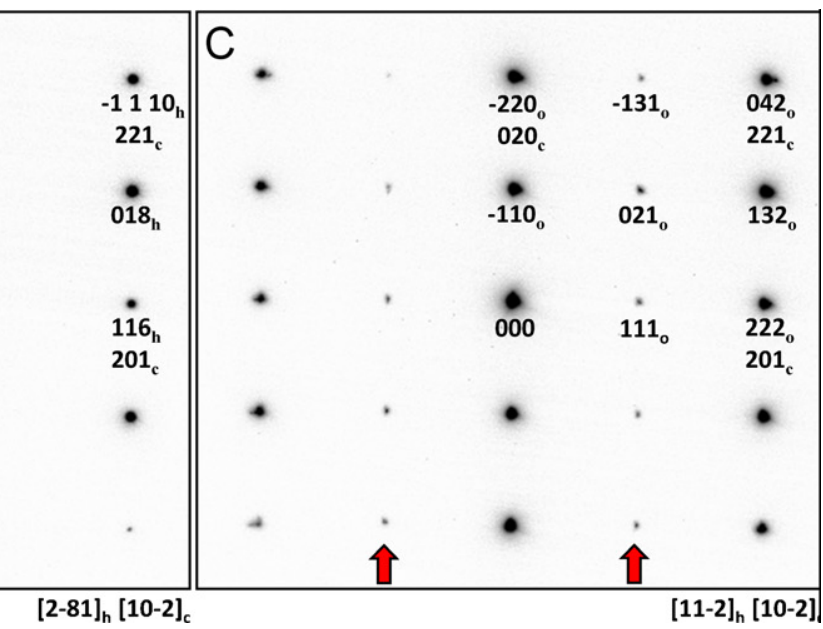

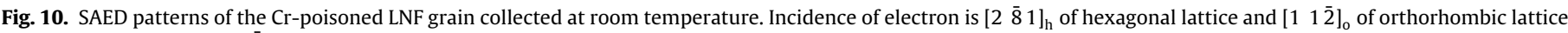
both corresponding to $\left[\begin{array}{lll}1 & 0 & 2\end{array}\right]_{c}$ of cubic lattice. The reflection spots indicated by arrows are derived from the orthorhombic lattice. 


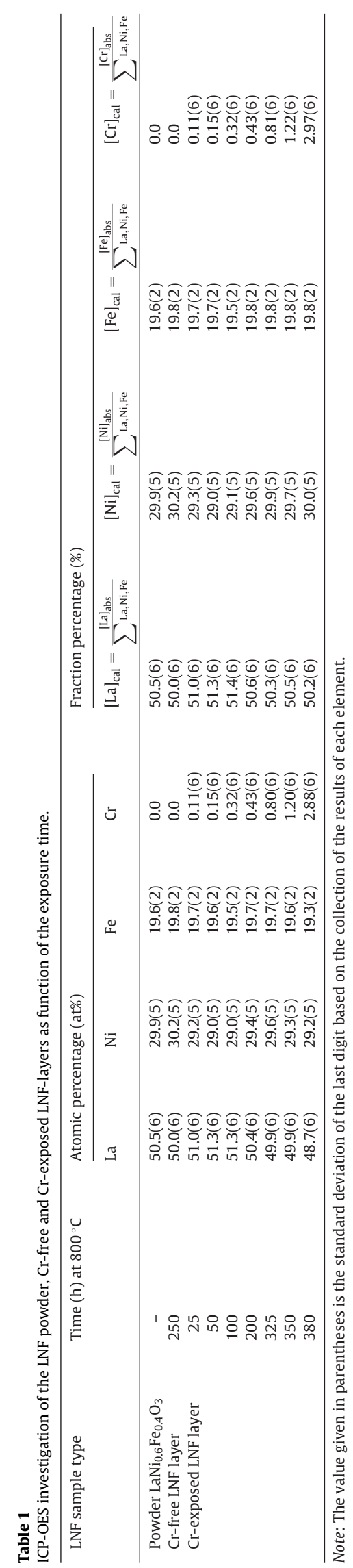

foams exposed longer, the outer scale was formed mainly by $\mathrm{Cr}_{2} \mathrm{O}_{3}$. The $\mathrm{Cr}$ vaporization from $(\mathrm{Mn}, \mathrm{Cr})_{2} \mathrm{O}_{4}$ layers is reduced due to a lower partial pressure of $\mathrm{CrO}_{x}$ species over $(\mathrm{Mn}, \mathrm{Cr})_{2} \mathrm{O}_{4}$ compared to $\mathrm{Cr}_{2} \mathrm{O}_{3}$ (for which $\mathrm{pCrO}_{x}$ is $\sim 1 \times 10^{-4} \mathrm{~Pa}$ at $800^{\circ} \mathrm{C}$ ) $[10,24,26]$. Such a change in the composition of the outer oxide scale of the porous ITM-14 foam will in consequence account for a different $\mathrm{Cr}$ release rate with time $[24,26]$ causing the observed sudden decrease in the electronic conductivity after $300 \mathrm{~h}$ (Fig. 4) together with the corresponding increased amount of deposited $\mathrm{Cr}$ (Table 1 and Fig. 6).

The distribution of $\mathrm{Cr}$ in the LNF layer exposed to volatile $\mathrm{Cr}$ species for $380 \mathrm{~h}$ at $800^{\circ} \mathrm{C}$ was provided by energy dispersive X-ray spectroscopy (EDX). Fig. 7 shows the SEM-EDX elemental mapping on an embedded and polished cross-section of the Cr-exposed LNF layer. The EDX-map demonstrates that $\mathrm{Cr}$ was evenly spread throughout the entire cross-section of the layer without observable significant areas of agglomeration, at least not visible with the available resolution of the used SEM-EDX technique (about $1 \mu \mathrm{m}^{3}$ ). Therefore, a technique offering higher spatial resolution, below the $1 \mu \mathrm{m}$ scale, is required to investigate the exact $\mathrm{Cr}$ location. For this purpose TEM-EDX (transmission electron microscopy-EDX) was used, as discussed in Section 3.4. The uniform elemental distribution of $\mathrm{Cr}$ throughout the $\mathrm{Cr}$-exposed LNF-layer, as observed by SEM-EDX, indicates that $\mathrm{Cr}$-species entered the porous LNF-layer via vapor phase transport. The driving force for the $\mathrm{Cr}$-deposition in the LNF-layer can be understood by comparing the enthalpies of formation and the relative thermodynamic stability of the perovskites: $\mathrm{LaCrO}_{3}>\mathrm{LaFeO}_{3}>\mathrm{LaNiO}_{3}$ [27], showing that the $\mathrm{Cr}$-containing perovskite is thermodynamically preferred over the LNF-phase.

Fig. 7 additionally shows the Ni elemental map which indicates that $\mathrm{Ni}$ was also detected everywhere in the layer, as expected on basis of the LNF-composition. However, there was a number of clearly visible spots with high Ni concentration. The locations of these submicron Ni-rich spots coincided with particles which had a sharp, cuboid-like appearance as observed in the SEM micrographs (Fig. 8). The standard Point-and-Shoot SEM-EDX analysis (with a $\sim 1 \mu \mathrm{m}^{3}$ excitation volume) performed on these particles showed a dominance of $\mathrm{Ni}$ and $\mathrm{O}$ signal in the EDX spectra, indicating the presence of Ni-rich metal oxide, which could be a perovskite, spinel, or pure $\mathrm{Ni}$ oxide. In comparison, the reference sample (shown in Fig. 2) contained only LNF particles with uniformly distributed elements and no Ni enriched spots could be found. This observation clearly indicates that the incorporation of $\mathrm{Cr}$ was accompanied with a segregation of $\mathrm{Ni}$ from $\mathrm{LNF}$, resulting in the formation of a $\mathrm{Ni}$ rich secondary oxide phase. The relatively large size of the Ni-rich crystals, found in the pores both on the surface and inside the $\mathrm{Cr}$ exposed porous LNF-layer (see Figs. 7 and 8), suggests that Ni could not exclusively originate from the adjacent grains and fast transport of Ni-species seemed to take place either by surface [28] or vapor diffusion mechanism [29-31].

\subsection{Cr distribution in a Cr-exposed LNF grain}

From the sample examined with SEM-EDX (Figs. 7 and 8) a section was taken to prepare a TEM-specimen for analysis of the $\mathrm{Cr}$ distribution within a single grain. A preliminary TEM screening of different locations was performed in order to select a representative grain for in-depth analyses by bright field TEM imaging (BF-TEM), selected area electron diffraction-TEM (SAED-TEM) and TEM-EDX.

\subsubsection{BF-TEM and TEM-EDX}

TEM-energy dispersive X-ray spectroscopy (TEM-EDX) in a Point-and-Shoot way (i.e. by focusing the electron beam with a spot diameter of $3.5 \mathrm{~nm}$ ) was performed on an electron transparent grain, at a distance of 10, 40 and $300 \mathrm{~nm}$ from the grain's edge 
as shown in the bright field TEM image (BF-TEM) in the right part of Fig. 9. The measurement was repeated 3 times in close vicinity of each spot to obtain a representative average of the elemental composition. Fig. 9 shows the $\mathrm{Ni}$, $\mathrm{Fe}$ and $\mathrm{Cr}$ concentrations detected in the corresponding distances from the grain's edge. The concentrations in atomic percentages of the A- and B-site constituents of the perovskite $\mathrm{ABO}_{3}$ (i.e. $\mathrm{La}, \mathrm{Ni}, \mathrm{Fe}$ and $\mathrm{Cr}$ ) were combined together to $100 \%$. On the basis of these TEM-EDX results it is possible to estimate a composition of the perovskite phase throughout the investigated grain. In the center of the grain $(300 \mathrm{~nm}$ spot) the approximate perovskite composition was $\mathrm{LaNi}_{0.59} \mathrm{Cr}_{0.00} \mathrm{Fe}_{0.40} \mathrm{O}_{3}$ which is close to the nominal $\operatorname{LNF}\left(\mathrm{LaNi}_{0.60} \mathrm{Fe}_{0.40} \mathrm{O}_{3}\right)$. This finding proves that the center of the grain was unaffected by $\mathrm{Cr}$. At a distance of $40 \mathrm{~nm}$ from the grain's edge the evaluated perovskite composition was $\mathrm{LaNi}_{0.39} \mathrm{Cr}_{0.24} \mathrm{Fe}_{0.36} \mathrm{O}_{3}$. Here, the Fe-content was almost unchanged but Ni was considerably depleted and substituted by $\mathrm{Cr}$. Close to the grain's edge ( $10 \mathrm{~nm}$ spot) the composition was estimated to be $\mathrm{LaNi}_{0.17} \mathrm{Cr}_{0.54} \mathrm{Fe}_{0.28} \mathrm{O}_{3}$, suggesting a slight $\mathrm{Fe}$ and a massive replacement of $\mathrm{Ni}$ by $\mathrm{Cr}$ which then occupied more than $50 \%$ of the B-site of the perovskite.

The observed gradients of $\mathrm{Ni}-$, $\mathrm{Fe}-$ and $\mathrm{Cr}-$, but constant Lacontent over the particle cross section, suggest that $\mathrm{Cr}$ diffused into the particle, while Ni diffused out of the particle. This result implies that $\mathrm{Cr}$ was incorporated into the LNF perovskite lattice as a solid solution.

\subsubsection{Electron diffraction (SAED-TEM)}

Selected area electron diffraction (SAED) was performed in order to investigate the influence of the incorporated $\mathrm{Cr}$ and removed $\mathrm{Ni}$ (and $\mathrm{Fe}$ ) on the crystal structure of the $\mathrm{Cr}$ affected grain. Two circles sketched on a BF-TEM image shown in Fig. 10A depict locations of the smallest available selected area aperture $(210 \mathrm{~nm}$ in diameter) for SAED.

Electron diffraction performed in the middle of the sliced grain proved to be the well known rhombohedral crystal structure of LNF (Fig. 10B), whereas SAED performed close to the edge of the grain revealed the presence of an orthorhombic perovskite crystal structure (Fig. 10C). The spots (marked by red arrows), indicating an orthorhombic symmetry, appeared only when an aperture area of the SAED was positioned close the grain's edge, which corresponded to the $\mathrm{Cr}$ induced structural phase transition from a rhombohedral to an orthorhombic perovskite distortion. A similar $\mathrm{Cr}$ impact on the LNF crystal structure was reported in case of solid-state reactivity of chromia with $\operatorname{LNF}[7,8]$. All the reflection spots in Fig. 10C could be indexed by assuming the rhombohedral cell with the hexagonal lattice parameters $a_{\mathrm{h}}=5.5 \AA$ and $c_{\mathrm{h}}=13.3 \AA$, where the suffix $h$ indicates a hexagonal system. In Fig. $10 \mathrm{C}$ all the reflections could be indexed as belonging to the orthorhombic cell (suffix o) with the parameters: $a_{0}=5.5 \AA, b_{0}=5.5 \AA, c_{0}=7.8 \AA$. The reflection spots indicated by arrows are typical for the orthorhombic lattice. In Fig. 10B and $\mathrm{C}$ the proper orthorhombic and hexagonal indices are also expressed in the cubic settings (suffix c). The fact that both SAED patterns can be indexed with the equivalent cubic cell suggests that the perovskite crystal orientation throughout the grain was preserved with only a crystal distortion induced by the $\mathrm{Cr}$ - and Ni-cation exchange. The presence of an orthorhombic phase at the edge of the grain and the presence of a rhombohedral phase in the bulk of the grain, detected with SAED at room temperature, corresponds to the observed gradient of $\mathrm{Cr}$ and Ni throughout the grain as described in the previous section.

\subsection{Conductivity evolution and $\mathrm{Cr}$ distribution at $600^{\circ} \mathrm{C}$}

To investigate the impact of the $\mathrm{Cr}$-exposure at lower temperatures, where reaction rates have decreased [7,8], a similar conductivity experiment was repeated at $600^{\circ} \mathrm{C}$. Fig. 11 shows the

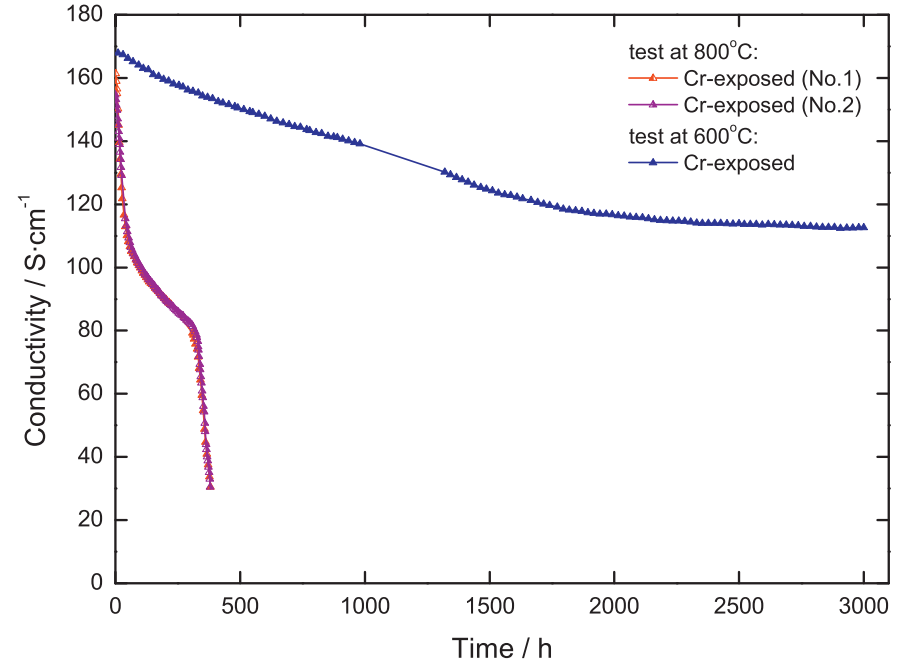

Fig. 11. The electronic conductivity evolution with time of LNF layers exposed to $\mathrm{Cr}$ at $600^{\circ} \mathrm{C}$ and $800^{\circ} \mathrm{C}$.

evolution of the electronic conductivity as function of time for the LNF layer exposed to volatile $\mathrm{Cr}$-species at $600^{\circ} \mathrm{C}$. For comparison, Fig. 11 contains also the results of the conductivity study at $800^{\circ} \mathrm{C}$. Compared to the samples exposed at $800^{\circ} \mathrm{C}$, the sample exposed at $600^{\circ} \mathrm{C}$ exhibited considerably smaller electronic conductivity drop, namely the electronic conductivity declined slowly in the first $2000 \mathrm{~h}$ to reach a semi-plateau between 2000 and $3000 \mathrm{~h}$ of the exposure. Only 30\% electronic conductivity was lost after $3000 \mathrm{~h}$ of the operation at $600^{\circ} \mathrm{C}$, in contrast with the $80 \%$ electronic conductivity loss after $380 \mathrm{~h}$ at $800^{\circ} \mathrm{C}$. An increased effective activation energy, of the small polaron hopping conduction, up to $0.15 \mathrm{eV}$ was also observed after the exposure of $3000 \mathrm{~h}$ at $600^{\circ} \mathrm{C}$.

Furthermore, SEM-EDX analysis on the Cr-exposed layer at $600^{\circ} \mathrm{C}$ also demonstrated the presence of small Ni-rich metal oxide crystals, similarly to those what had been observed in the $800^{\circ} \mathrm{C}$ case. However, the amount of $\mathrm{Cr}$ deposited in the layer during $3000 \mathrm{~h}$ exposure to volatile $\mathrm{Cr}$-species at $600^{\circ} \mathrm{C}$ was considerably smaller than during $380 \mathrm{~h}$ exposure at $800^{\circ} \mathrm{C}$. ICP-OES results showed a huge difference between exposure at 600 and $800^{\circ} \mathrm{C}$, with $\mathrm{Cr}$ content values of 0.30 at\% (after $3000 \mathrm{~h}$ at $600^{\circ} \mathrm{C}$ ) and $2.88 \mathrm{at} \%$ (after $380 \mathrm{~h}$ at $800^{\circ} \mathrm{C}$ ).

The observed deterioration of the electronic conductivity occurring both at $800^{\circ} \mathrm{C}$ and $600^{\circ} \mathrm{C}$ suggests that a comparable conductivity degradation mechanism took place at both considered operating temperatures. However, the significant differences in the electronic conductivity loss indicate that the poisoning process was happening at different rates. This could be due to the thermally induced differences: (i) in the amount of $\mathrm{Cr}$ species released by the Cr-source and/or (ii) in the rate of $\mathrm{Cr}$ diffusion into the LNF grain. The $\mathrm{Cr}$ evaporation rate (i) is influenced by the exposure conditions: the partial pressures of different $\mathrm{Cr}$-species, over $\mathrm{Cr}_{2} \mathrm{O}_{3(\mathrm{~s})}$ in dry air, decrease with temperature [10]. Therefore, vapor supply of $\mathrm{Cr}$ into the porous body of the LNF layer is smaller at $600^{\circ} \mathrm{C}$ than at $800^{\circ} \mathrm{C}$. Furthermore, the cation diffusivity in the perovskite lattice (ii) is known to decrease substantially with temperature [32] This accounts for a lower diffusion rate of $\mathrm{Cr}$ - and $\mathrm{Ni}$-ions in the LNF grains. Consequently, at $600^{\circ} \mathrm{C}$ the reaction rates and the background pressure of the volatile $\mathrm{Cr}$-species are significantly reduced as all rate limiting processes are thermally activated.

Even at $600^{\circ} \mathrm{C}$ the electronic conductivity loss is evident (Fig. 11) but at a much slower rate. Taking into account that in the present study the $\mathrm{Cr}$-poisoning conditions were deliberately severe, under actual SOFC operation conditions the $\mathrm{Cr}$ deposition might be significantly lower due to the continuous airstream. This would lead to a 


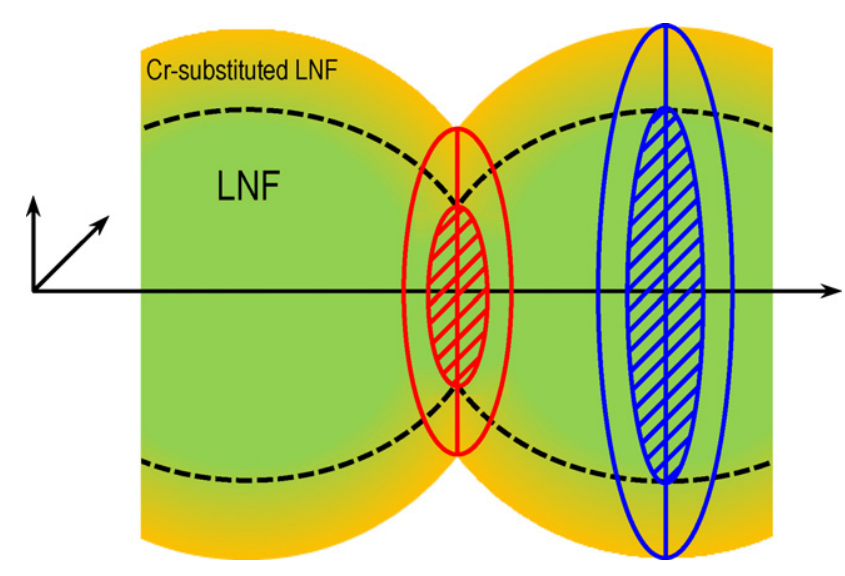

Fig. 12. A schematic drawing of the $\mathrm{Cr}$-affected LNF particle-neck-particle sequence representing the smallest repeating unit in a percolating network of the porous LNF-layer.

much lower loss rate for the electronic conductivity. Nevertheless, the impact of $\mathrm{Cr}$ on the catalytic activity and the surface exchange rate needs further investigation to prove LNF feasibility at $600^{\circ} \mathrm{C}$.

\subsection{Phenomenological description of the conductivity loss triggered by the Cr-intrusion}

The observed loss in the in-plane electronic conductivity (Figs. 4 and 11) of the LNF porous layer, under a constant exposure to $\mathrm{CrO}_{x}$ rich atmosphere, was clearly due to an exchange between $\mathrm{Cr}$ and $\mathrm{Ni}$ in the LNF-particles in the porous LNF-layer (Sections 3.2-3.5). The in-plane conductivity of the porous LNF-layer can be described by a percolating network of conducting LNF particles, which are connected to each other by necks, formed during the sintering step in the manufacturing procedure. The smallest repeating unit in such a percolating network is the particle-neck-particle sequence as shown in Fig. 12. The Cr-substituted LNF phase, formed in the outer shell of the LNF particles and necks during $\mathrm{Cr}$-exposure (as schematically shown in Fig. 12), has a significantly lower electronic conductivity $[20,21]$ compared to a Ni-rich LNF phase $[1,18]$.

As a consequence the $\mathrm{Cr}$-intrusion results in a lower volume of a well conducting LNF-phase causing a decrease in the overall in-plane conductivity of the porous LNF-layer. When assuming a $\mathrm{Cr}$ intrusion depth of circa $100 \mathrm{~nm}$ (Fig. 9) it can be calculated (based on Fig. 3B) that $\sim 54 \%$ area of the grains' cross-section has been affected by the $\mathrm{Cr}$-intrusion. In addition also the necks between the grains are affected by the $\mathrm{Cr}$-intrusion, where the effect on the neck is expected to be large due to the smaller diameter (Fig. 3) and thus a relatively large part of the neck cross-section contains the $\mathrm{Cr}$-containing phase. Indeed, assuming the $\mathrm{Cr}$-intrusion of $100 \mathrm{~nm}$, a simple calculation indicates that $\sim 73 \%$ of the necks' cross-section area is affected by $\mathrm{Cr}$ compared to mentioned $\sim 54 \%$ of the grains' cross-section area.

On the base of this phenomenological description of the conductivity loss one can expect that the particle size distribution will have a considerable influence on the rate and the magnitude of the electronic conductivity loss, caused by the volatile $\mathrm{Cr}$ species attack. The microstructure related aspect of $\mathrm{Cr}$-poisoning will be discussed in a follow-up paper [33].

\section{Conclusions}

Based on the presented observations the following mechanism has been derived for the impact of $\mathrm{Cr}$-poisoning on the electronic conductivity of the LNF layer:
(1) Cr vapor species directly reacts with LNF at IT-SOFC operating temperatures. The $\mathrm{Cr}$-attack at the LNF grain surface comprises a replacement of $\mathrm{Ni}$ by $\mathrm{Cr}$ in the perovskite lattice.

(2) The Cr-rich phase transforms from a rhombohedral to an orthorhombic crystal structure, confirming the exchange of $\mathrm{Ni}$ by $\mathrm{Cr}$.

(3) The drop in the in-plane conductivity of the porous LNF-layer is caused by the significantly lower electronic conductivity of the $\mathrm{Cr}$-rich phase, made worse at the constricted necks of the grains, where higher concentrations of $\mathrm{Cr}$ are likely to exist due to their higher surface to volume ratios.

(4) The segregated nickel, replaced by chromium in the LNF bulk, forms Ni-rich metal oxide precipitates in the pores.

(5) Cr-poisoning impact on the LNF conductivity is smaller at $600^{\circ} \mathrm{C}$ than at $800^{\circ} \mathrm{C}$.

During full SOFC-stack operation, the actual LNF ageing rate, due to $\mathrm{Cr}$-poisoning seems to be significantly lower [12] as the relative area of the $\mathrm{Cr}$-source is much smaller. The continuous air flow will also affect the $\mathrm{Cr}$-background pressure.

\section{Acknowledgements}

This work was partly supported by the European Commission, as part of the European Project SOFC600 (SES6-CT-2006-020089), and partly supported by funding from ECN. Adrien Signolet is acknowledged for his involvement in this study during his traineeship at ECN. Jan Pieter Ouweltjes and Wim Haije are thanked for helpful discussions and comments. ECN Engineering \& Services (Materials Testing \& Consultancy group) is thanked for the SEM-EDX and ICPOES analysis. Enrico G. Keim (MESA+ Institute NanoLab, University of Twente) is gratefully acknowledged for assistance with the TEM analyses.

\section{References}

[1] R. Chiba, F. Yoshimura, Y. Sakurai, Solid State Ionics 124 (1999) 281

[2] T. Komatsu, H. Arai, R. Chiba, K. Nozawa, M. Arakawa, K. Sato, Electrochem. Solid-State Lett. 9 (2006) A9J.

[3] Y.D. Zhen, A.I.Y. Tok, S.P. Jiang, F.Y.C. Boey, J. Power Sources 170 (2007) 61.

[4] G.Y. Laua, M.C. Tucker, C.P. Jacobson, S.J. Visco, S.H. Gleixner, L.C. DeJonghe, J. Power Sources 195 (2010) 7540.

[5] M.C. Tucker, J. Power Sources 195 (2010) 4570.

[6] H. Orui, K. Watanabe, R. Chiba, M. Arakawa, J. Electrochem. Soc. 151 (2004) A1412.

[7] M. Stodolny, F.P.F. van Berkel, B.A. Boukamp, ECS Trans. 25 (2) (2009) 2915-2922.

[8] M.K. Stodolny, B.A. Boukamp, D.H.A. Blank, F.P.F. van Berkel, J. Electrochem. Soc. 158 (2) (2011) B112-B116.

[9] M.C. Tucker, H. Kurokawa, C.P. Jacobson, L.C. De Jonghe, S.J. Visco, J. Power Sources 160 (2006) 130.

[10] K. Hilpert, D. Das, M. Miller, D.H. Peck, R. Weiss, J. Electrochem. Soc. 143 (1996) 3642.

[11] F.P.F. van Berkel, M. Stodólny, M. Sillessen, J.P. Ouweltjes, Proceedings of the 8th European Solid Oxide Fuel Cell Forum, vol. A0621, European Fuel Cell Forum, 2008, pp. 1-9.

[12] M.K. Stodolny, B.A. Boukamp, D.H.A. Blank, F.P.F. van Berkel, submitted for publication.

[13] J.P. Ouweltjes, M. van Tuel, M. Sillessen, G. Rietveld, Fuel Cells 9 (2009) 873.

[14] J.Y. Chen, et al., Solid State Ionics (2010), doi:10.1016/j.ssi.2010.04.019.

[15] W. Glatz, G. Kunschert, M. Janousek, in: M. Mogensen (Ed.), Proc. 6th European Solid Oxide Fuel Cell Forum, European Fuel Cell Forum, Switzerland, 2004.

[16] W. Glatz, G. Kunschert, et al., Electrochemical Society Proceedings, vol. 1, 2005-07, 9th International Symposium on Solid Oxide Fuel Cells, Quebec City, Canada, 2005, ISBN 1-56677-466-7, pp. 1773/1780.

[17] M.D. Abramoff, P.J. Magelhaes, S.J. Ram, Biophoton. Int. 11 (2004) 36-42.

[18] M. Bevilacqua, T. Montini, C. Tavagnacco, G. Vicario, P. Fornasiero, M. Graziani, Solid State Ionics 177 (2006) 2957.

[19] E. Konysheva, J.T.S. Irvine, J. Power Sources 193 (2009) 175.

[20] H.E. Höfer, R. Schmidberger, J. Electrochem. Soc. 141 (1994) 782.

[21] R. Koc, H.U. Anderson, J. Eur. Ceram. Soc. 15 (1995) 867-874.

[22] K. Iwasaki, T. Ito, M. Yoshino, T. Matsui, T. Nagasaki, Y. Arita, J. Alloys Compd. 430 (2007) 297-301.

[23] A. Berenov, E. Angeles, J. Rossiny, E. Raj, J. Kilner, A. Atkinson, Solid State Ionics 179 (2008) 1090-1093. 
[24] M. Stanislowski, J. Froitzheim, L. Niewolak, W.J. Quadakkers, K. Hilpert, T. Markus, L. Singheiser, J. Power Sources 164 (2007) 578-589.

[25] F.P.F. van Berkel, G. Schoemakers, G. Rietveld, ECN Internal Communication.

[26] E. Konysheva, U. Seeling, A. Besmehn, L. Singheiser, K. Hilpert, J. Mater. Sci. 42 (14) (2007) 5778-5784.

[27] J. Cheng, A. Navrotsky, X. Zhou, H.U. Anderson, J. Mater. Res. 20 (1) (2005) 191.
[28] I. Beszeda, D.L. Beke, Yu. Kaganovskii, Surf. Sci. 569 (1-3)(2004) 5-11.

[29] R.T. Grimley, R.P. Burns, M.G. Inghram, J. Chem. Phys. 35 (2) (1961) 551-554.

[30] G.R. Belton, A.S. Jordan, J. Phys. Chem. 71 (12) (1967) 4114-4120.

[31] W.S. Chang, P. Shen, S. Chen, Mater. Sci. Eng. A148 (1991) 145.

[32] S. Miyoshi, M. Martin, Phys. Chem. Chem. Phys. 11 (2009) 3063

[33] M.K. Stodolny, B.A. Boukamp, D.H.A. Blank, F.P.F. van Berkel, Solid State Ionics, submitted for publication. 